\title{
Global gene expression under nitrogen starvation in Xylella fastidiosa: contribution of the $\sigma^{54}$ regulon
}

\author{
José $\mathrm{F}$ da Silva Neto ${ }^{1 *}$, Tie Koide ${ }^{2,3}$, Suely L Gomes ${ }^{2}$, Marilis V Marques
}

\begin{abstract}
Background: Xylella fastidiosa, a Gram-negative fastidious bacterium, grows in the xylem of several plants causing diseases such as citrus variegated chlorosis. As the xylem sap contains low concentrations of amino acids and other compounds, X. fastidiosa needs to cope with nitrogen limitation in its natural habitat.

Results: In this work, we performed a whole-genome microarray analysis of the $X$. fastidiosa nitrogen starvation response. A time course experiment (2,8 and 12 hours) of cultures grown in defined medium under nitrogen starvation revealed many differentially expressed genes, such as those related to transport, nitrogen assimilation, amino acid biosynthesis, transcriptional regulation, and many genes encoding hypothetical proteins. In addition, a decrease in the expression levels of many genes involved in carbon metabolism and energy generation pathways was also observed. Comparison of gene expression profiles between the wild type strain and the rpoN null mutant allowed the identification of genes directly or indirectly induced by nitrogen starvation in a $\sigma^{54}$-dependent manner. A more complete picture of the $\sigma^{54}$ regulon was achieved by combining the transcriptome data with an in silico search for potential $\sigma^{54}$-dependent promoters, using a position weight matrix approach. One of these $\sigma^{54}$ predicted binding sites, located upstream of the glnA gene (encoding glutamine synthetase), was validated by primer extension assays, confirming that this gene has a $\sigma^{54}$-dependent promoter.
\end{abstract}

Conclusions: Together, these results show that nitrogen starvation causes intense changes in the $X$. fastidiosa transcriptome and some of these differentially expressed genes belong to the $\sigma^{54}$ regulon.

\section{Background}

Xylella fastidiosa colonizes the xylem elements of many plants, causing diseases in economically important crops, such as citrus variegated chlorosis in citrus species and Pierce's disease in grapevines [1]. This Gramnegative fastidious bacterium, transmitted by sap-feeding insect vectors, utilizes a plethora of virulence determinants such as adhesins, type IV pili, gum and extracellular cell wall-degrading enzymes to efficiently colonize the plant xylem [2].

It has been shown that the xylem fluid affects planktonic growth, biofilm formation and aggregation of $X$. fastidiosa $[3,4]$. Xylem is a nutrient-poor environment

\footnotetext{
* Correspondence: jfsneto@usp.br

'Departamento de Microbiologia, Instituto de Ciências Biomédicas, Universidade de São Paulo, Av. Prof. Lineu Prestes 1374, 05508-000 São Paulo, SP, Brazil

Full list of author information is available at the end of the article
}

that contains low concentrations of diverse compounds such as amino acids, organic acids, and inorganic nutrients. Amino acids are the main nitrogen source in xylem fluid of plants, predominantly glutamine and asparagine [5]. Recently, it was determined that glutamine predominates in the xylem sap of grapevine (Vitis vinifera) [3] while asparagine and glutamine are found in larger quantity in the xylem sap of citrus (Citrus sinensis) [6]. In infected plants, X. fastidiosa grows exclusively in the xylem vessels, where it must cope with nitrogen limitation and be able to utilize amino acids as nitrogen source. Although it has been determined that $X$. fastidiosa disturbs nitrogen metabolism of infected orange trees [6], no aspect of the nitrogen metabolism has been investigated in this phytopathogen.

The global response to nitrogen starvation has been studied at the transcriptional level in several bacteria, such as Corynebacterium glutamicum [7], Synechocystis
C Biomed Central

(c) 2010 da Silva Neto et al; licensee BioMed Central Ltd. This is an Open Access article distributed under the terms of the Creative Commons Attribution License (http://creativecommons.org/licenses/by/2.0), which permits unrestricted use, distribution, and reproduction in any medium, provided the original work is properly cited. 
sp. [8], Prochlorococcus [9] and Anabaena sp. [10]. The regulation of nitrogen metabolism is well-established in several model organisms, such as Escherichia coli, Bacillus subtilis and Corynebacterium glutamicum [11]. In E. coli and other enterobacteria, nitrogen limitation causes changes in expression of about 100 genes, whose products are involved in ammonium assimilation and scavenging for nitrogen-containing compounds [12]. Most of these genes are transcribed by the RNA polymerase containing the sigma factor RpoN $\left(\sigma^{54}\right)$ and activated by the nitrogen regulatory protein $\mathrm{C}(\mathrm{N} \operatorname{trC})$. The NtrC-RpoN regulon includes at least 14 operons, among them $\operatorname{gln} A n \operatorname{tr} B C$ (glutamine synthetase and the twocomponent system NtrB-NtrC), glnK-amtB (PII signal transduction protein and ammonium transporter), ast$C A D B E$ (arginine catabolism), $g \ln H P Q$ (glutamine transport) and $n a c$ ( $\sigma^{70}$-dependent transcriptional activator) $[12,13]$. On the other hand, in the oligotrophic alphaproteobacterium Caulobacter crescentus $\sigma^{54}$ does not regulate the majority of genes induced under nitrogen limitation [14].

Although the most prevalent RpoN-regulated function in bacteria is nitrogen assimilation, this alternative sigma factor controls many distinctive and unrelated cellular functions, such as pili and flagella biosynthesis, plant pathogenicity, catabolism of aromatic compounds and nitrogen fixation [15]. This is possible because $\sigma^{54}$ utilizes diverse transcription activators called enhancerbinding proteins (EBPs), all governed by their own signal pathways, for initiation of transcription [16]. Besides the absolute dependence of EBPs and ATP hydrolysis for the formation of the RNA polymerase open complex on the promoters, another unique feature of $\sigma^{54}$ is the recognition of -24/-12-type promoters with consensus sequence TGGCACG-N4-TTGC $[17,18]$. The $\sigma^{54}$ regulon was estimated in several organisms, such as E. coli [19], Pseudomonas putida [20] and several species of Rhizobiaceae [21] by use of powerful computational methods that took advantage of the high conservation of $\sigma^{54}$ promoter sequences throughout diverse bacterial groups.

Alternative sigma factors provide effective mechanisms for regulating a large numbers of genes in response to several environmental stresses. In the genome of $X$. fastidiosa there are genes encoding each of the sigma factors RpoD, RpoH, RpoE and RpoN [22]. Large-scale studies using microarrays and in silico analyses have permitted to determine the $\mathrm{RpoH}$ and RpoE regulons and their contribution to the heat shock response $[23,24]$. Recently, we have established that RpoN controls cell-cell aggregation and biofilm formation in $X$. fastidiosa by means of differential regulation of genes involved in type I and type IV fimbrial biogenesis. We have also characterized the first $\sigma^{54}$-dependent promoter in X. fastidiosa, controlling expression of the pilA1 gene [25].

Here, we analyzed the global transcriptional profile of $X$. fastidiosa under nitrogen starvation conditions using DNA microarrays. A more complete description of the $X$. fastidiosa $\sigma^{54}$ regulon was achieved using microarray data from an rpoN mutant integrated with an in silico analysis of RpoN-binding sites. The regulatory region of the $g \ln A$ gene that encodes the enzyme glutamine synthetase was further characterized, and confirmed to have a $\sigma^{54}$-dependent promoter, suggesting an important role of ammonium assimilation mediated by $\sigma^{54}$ in X. fastidiosa.

\section{Methods}

\section{Bacterial strains and growth conditions}

The citrus strain J1a12 of Xylella fastidiosa [26] was cultivated in PW medium [27] without bovine serum albumin and phenol red and supplemented with $0.5 \%$ glucose (w/v) (PWG) at $25^{\circ} \mathrm{C}$ with no agitation. Cultures were also grown in defined $\mathrm{XDM}_{2}$ medium [28] or $\mathrm{XDM}_{2}$ medium lacking all nitrogen sources $\left(\mathrm{XDM}_{0}\right)$ at the same conditions. For the rpoN mutant strain [25], $10 \mu \mathrm{g}$ ampicillin $\mathrm{ml}^{-1}$ was supplemented to the PWG medium.

\section{Growth of Xylella cells in nitrogen starvation}

For time course studies, late-exponential phase cells in PWG medium were used to inoculate a culture in 100 $\mathrm{ml} \mathrm{XDM} \mathrm{X}_{2}$ medium to an optical density at $600 \mathrm{~nm}$ $\left(\mathrm{OD}_{600} \mathrm{~nm}\right)$ of 0.1 . Cells were grown during 12 days in the $\mathrm{XDM}_{2}$ medium (mid-log phase) and harvested by centrifugation. Then, the culture was divided into two portions: in one the cells were washed with $\mathrm{XDM}_{2}$ medium, collected by centrifugation and rapidly frozen in dry ice (this aliquot was considered the time zero of the experiment). The second portion was washed with $\mathrm{XDM}_{0}$ medium and the cultivation was continued for $2 \mathrm{~h}, 8 \mathrm{~h}$ and $12 \mathrm{~h}$ in $\mathrm{XDM}_{0}$ medium to establish nitrogen starvation conditions. For each time point, cells in a 25 - $\mathrm{ml}$ culture were collected by centrifugation and rapidly frozen in dry ice, until RNA isolation.

\section{Preparation of RNA for DNA microarray}

Total RNA was isolated from $X$. fastidiosa wild type and rpoN mutant cells, grown under nitrogen excess or nitrogen starvation conditions as described above, using the TRIZOL reagent (Invitrogen), according to the manufacturer's instructions. DNA was removed using RQ1 DNase I (Promega). RNA samples were evaluated by electrophoresis on formaldehyde-agarose gels and stored at $-80^{\circ} \mathrm{C}$. Microarray slides covering more than $94 \%$ of all $X$. fastidiosa genes, spotted at least in duplicate, were prepared as previously described [29]. Fluorescent- 
labeled cDNA preparation, microarray hybridization, washing and scanning were performed as previously described [25]. The ArrayVision version 6.0 software (Imaging Research, Inc.) was used for spot finding and signal-intensity quantification. Three RNA samples isolated from independently grown cultures of the cells at each starvation period ( $2 \mathrm{~h}, 8 \mathrm{~h}$ and $12 \mathrm{~h}$ ) were examined, and each preparation was subjected to microarray analysis. As the genes were spotted at least in duplicate, we obtained six replicates for each gene from three independent data sets per gene per starvation period. Normalization was carried out using the LOWESS algorithm [30]. Differentially expressed genes were identified using intensity-dependent cutoff values based on selfself hybridization experiments [31]. A gene was classified as upregulated or downregulated if at least four of six replicates were outside of the intensity-dependent cutoff curves. Microarray data are available at the NCBI GEO (Gene Expression Omnibus) database http://www. ncbi.nlm.nih.gov/geo, with accession number GSE21647.

\section{Primer extension analysis}

Primer extension assays were performed as previously described [25], using $50 \mu \mathrm{g}$ of RNA as template isolated from J1a12 or rpoN cells grown in PWG. Total RNA was hybridized to the $\left[\gamma_{-}{ }^{32} \mathrm{P}\right] \mathrm{ATP}$-labeled primer XF1842EXT (5'-AACAAAGCGCAAATCGACGAAT TCG-3') and extended with the Superscript III reverse transcriptase (Invitrogen). The sequencing ladder was generated with the Thermo Sequenase cycle sequencing kit (USB), using the $\left[\gamma^{32} \mathrm{P}\right] \mathrm{ATP}$-labeled primer M13Forward (5'-GTAAAACGACGGCCAGT -3') and M13 DNA template.

\section{Computational prediction of $\sigma^{54}$-dependent promoter sequences}

A position weight-matrix was constructed using a set of 186 RpoN-dependent promoters from different bacterial species [18]. This matrix was used to perform a genome-wide screening for putative RpoN-binding sites in the $X$. fastidiosa genome sequence [22] with the PATSER module [32] from the Regulatory Sequence Analysis Tools (RSAT) website [33]. The search for putative RpoN-binding sites was restricted to intergenic regions (non-coding region between two genes) on the coding strand of all annotated genes. Sequence logos were generated using the WebLogo package [34].

\section{Results and Discussion}

\section{Transcriptome of Xylella cells grown under nitrogen} starvation

In this work, DNA microarray experiments were used to reveal the global transcriptional profile of $X$. fastidiosa under nitrogen starvation conditions. The experiments compared changes in the expression profile of cells growing in the absence of nitrogen $\left(\mathrm{XDM}_{0}\right.$ medium) for 2, 8 and 12 hours compared to cells maintained in defined medium containing amino acids serine, methionine, asparagine and glutamine as nitrogen source $\left(\mathrm{XDM}_{2}\right.$ medium, zero-time). The relative ratio was calculated for the zero-time sample compared with each time-point sample and data from each point correspond to three independent biological replicates. The complete list of differentially expressed genes is provided in Additional file 1: Table S1 and Additional file 2: Table S2.

We identified 448 differentially expressed genes at one or more time-points following nitrogen starvation and among them, 252 genes were upregulated, whereas 196 genes were downregulated (Additional file 1: Table S1 and Additional file 2: Table S2). Very few genes were up- or down-regulated during all three time-points of nitrogen starvation: 7 genes were induced and 9 genes were repressed (intersection of the three circles in Figure 1). The cumulative number of induced genes in cells exposed to $2 \mathrm{~h}, 8 \mathrm{~h}$ and $12 \mathrm{~h}$ of nitrogen starvation were 77,156 and 132, respectively, while the number of repressed genes were 19,139 and 128 , respectively (numbers in gray ovals; Figure 1). These data indicate that the number of differentially expressed genes increased substantially from $2 \mathrm{~h}$ to $8 \mathrm{~h}$ and began to decline at the $12 \mathrm{~h}$ time point, indicating that the temporal series covered a wide range of genes with altered expression in response to nitrogen starvation.

The genes differentially expressed under nitrogen starvation were classified into functional classes according to the categories defined in the original annotation of the $X$. fastidiosa genome [22] based on the annotation of $E$. coli genes [35] (Table 1). There are genes belonging to all categories, but some categories are overrepresented, such as RNA metabolism (30 genes), biosynthesis of amino acids (23 genes), energy and carbon metabolism (20 genes), transport (20 genes) and protein metabolism (19 genes) (Table 1). Categories with predominance of induced genes include regulatory functions and phage-related functions and prophages. On the other hand, categories with prevalence of repressed genes compared to induced genes are mainly related to metabolism, such as central intermediary metabolism, energy metabolism and protein metabolism (Table 1). Putative functions of some of these differentially expressed genes in response to nitrogen starvation are described below.

\section{Transport}

Changes in expression of 20 genes encoding proteins related to transport ( 8 induced genes and 12 repressed genes) seem to indicate that adjustment of the transport capacity is an important cellular response to nitrogen starvation. There is a predominance of ATP-Binding 

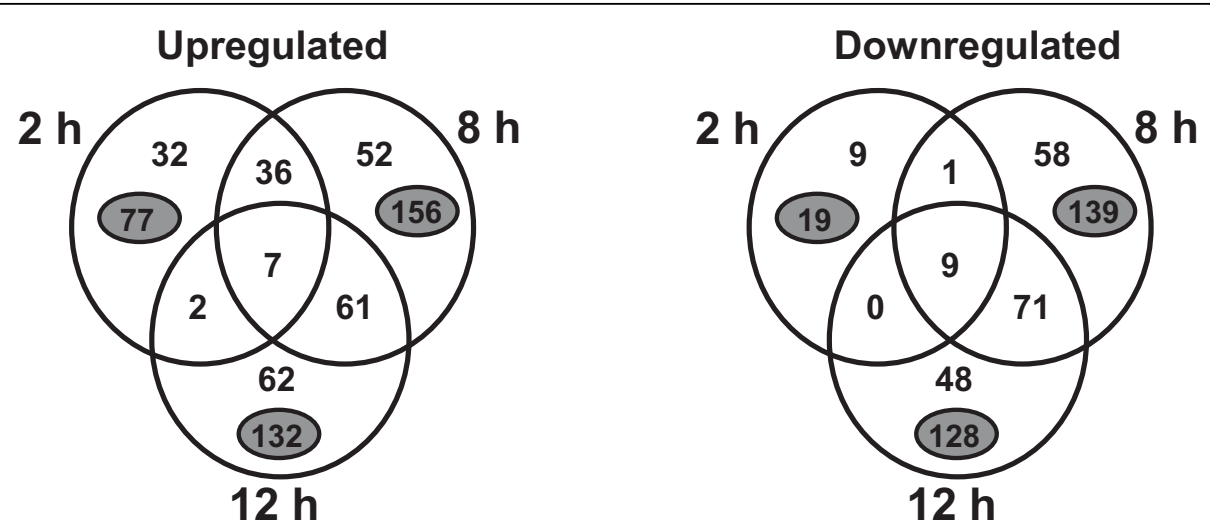

Figure 1 Diagram summarizing the number of differentially expressed genes in X. fastidiosa J1a12 under nitrogen starvation. Large circles represent each one of the three time-points. Numbers in the circles indicate genes with differential expression at each specific time-point and in more than one time-point (regions of intersection). Numbers in the small gray ovals indicate the total of the differentially expressed genes for each time-point (i.e. the sum of the genes in each large circle). The circles and regions of overlap are not drawn to scale.

Cassette $(\mathrm{ABC})$ transporters, possibly involved in the transport of sugars, amino acids and iron, based on sequence annotation (Additional file 1: Table S1 and Additional file 2: Table S2). In E. coli [13] and Corynebacterium glutamicum [11] the induction of transport systems of various alternative nitrogen sources is one of the main responses to nitrogen starvation. The repression of genes encoding transporters in $X$. fastidiosa seems to be an adaptation to long time nitrogen starvation, since most of the 12 downregulated genes were repressed only at the $12 \mathrm{~h}$ time point (Table 1 and Additional file 2: Table S2).

\section{Carbon and energy metabolism}

In this category, 17 of the 20 differentially expressed genes under nitrogen starvation were repressed, most of them in the $8 \mathrm{~h}$ and $12 \mathrm{~h}$ periods (Table 1 and Additional file 2: Table S2). Genes of the major pathways of carbon and energy metabolism were repressed, including three genes of glycolysis ( $p f k A, g a p A$ and $f b a B$ ), a gene of the enzyme pyruvate dehydrogenase (aceE), seven genes of the Krebs cycle ( $a c n B, s d h B, l p d, s u c B$, odhA, sucC and $s u c D$ ), four genes of the electron-transport chain (etfA, etfB, etf-QO and $c y o C)$ and two genes of the enzyme ATP synthase (atpA and $a t p D$ ). Downregulation of many genes related to carbon and energy metabolism was also observed when $X$. fastidiosa cells were exposed to prolonged high temperature [23] suggesting that this is a common response to long time stress conditions. However, genes for sugar catabolic pathways are induced by nitrogen depletion in the cyanobacterium Synechocystis sp. [8] and genes encoding glycolytic enzymes and respiratory chain components are upregulated during ammonium limitation in C. glutamicum, maybe due to the necessity of an increased ATP production during nitrogen starvation for ammonium assimilation via the GS/GOGAT pathway [36].

\section{Nitrogen metabolism and biosynthesis of amino acids}

After two hours of nitrogen starvation, we observed an increase in transcript levels of genes gltD (XF2709) and gltB (XF2710), encoding the two subunits of the enzyme glutamate synthase (GOGAT), while the expression levels of the $g \ln A$ gene (XF1842), encoding the enzyme glutamine synthetase (GS), was not altered (Additional file 1: Table S1). Assimilation of ammonium by means of the high-affinity GS/GOGAT pathway is more effective than assimilation by the enzyme glutamate dehydrogenase $(\mathrm{GDH})$, under nitrogen limitation. In fact, the genes encoding GS/GOGAT are upregulated under nitrogen limitation in several bacteria $[12,7]$. We observed induction of only few genes encoding enzymes involved in catabolism of amino acids or proteins, such as rocF (arginine deaminase), $t d c B$ (threonine dehydratase), pip (proline iminopeptidase) and pepQ (proline dipeptidase) (Additional file 1: Table S1), suggesting that $X$. fastidiosa might scavenge nitrogen compounds as a secondary mechanism to ameliorate nitrogen starvation. The biosynthesis of amino acids was significantly affected, with 13 genes being induced and 10 genes being repressed (Table 1). However, this may reflect the fact that nitrogen starvation experiments were carried out in $\mathrm{XMD}_{2}$ medium, that contain amino acids (Ser, Met, Asp and Gln). The induced genes encode enzymes that are part of biosynthesis pathways of glutamate, methionine and cysteine, and their induction is probably not related to nitrogen starvation per se, but instead by the removal of these particular amino acids from the medium.

Additionally, the genes encoding RelA and SpoT, two different ppGpp synthetases that produce the nucleotide alarmone ppGpp in response to amino acids or carbon starvation [37], were induced after $2 \mathrm{~h}$ and $8 \mathrm{~h}$ of starvation. This upregulation seems to be a sign 
Table 1 Functional classification of differentially expressed genes under nitrogen starvation in $X$. fastidiosa.

\begin{tabular}{|c|c|c|c|}
\hline \multirow[t]{2}{*}{ Functional Category* } & \multirow[b]{2}{*}{$2 \mathrm{~h}$} & \multicolumn{2}{|c|}{ Temporal series ${ }^{\S}$} \\
\hline & & $8 \mathrm{~h}$ & $12 \mathrm{~h}$ \\
\hline \multicolumn{4}{|l|}{ Intermediary metabolism (25/34) } \\
\hline Degradation (5/3) & $2 / 0$ & $1 / 3$ & $2 / 2$ \\
\hline Central intermediary metabolism (5/10) & $4 / 0$ & $2 / 7$ & $3 / 6$ \\
\hline Energy metabolism, carbon (3/17) & $1 / 2$ & $3 / 16$ & $0 / 14$ \\
\hline Regulatory functions (12/4) & $4 / 1$ & $9 / 2$ & $5 / 2$ \\
\hline \multicolumn{4}{|l|}{ Biosynthesis of small molecules $(28 / 25)$} \\
\hline Amino acids biosynthesis $(13 / 10)$ & $9 / 1$ & $8 / 7$ & $3 / 4$ \\
\hline Nucleotides biosynthesis (2/5) & $0 / 0$ & $1 / 2$ & $2 / 5$ \\
\hline Sugars and sugar nucleotides biosynthesis $(0 / 1)$ & $0 / 0$ & $0 / 1$ & $0 / 0$ \\
\hline Cofactors, prosthetic groups, carriers biosynthesis (8/5) & $2 / 0$ & $6 / 4$ & $2 / 3$ \\
\hline Fatty acid and phosphatidic acid biosynthesis (4/4) & $2 / 0$ & $2 / 2$ & $1 / 3$ \\
\hline Polyamines biosynthesis $(1 / 0)$ & $0 / 0$ & $0 / 0$ & $1 / 0$ \\
\hline \multicolumn{4}{|l|}{ Macromolecule metabolism (28/37) } \\
\hline DNA metabolism (8/8) & $1 / 1$ & $5 / 4$ & $7 / 4$ \\
\hline RNA metabolism (17/13) & $3 / 0$ & $13 / 11$ & $11 / 9$ \\
\hline Protein metabolism (3/16) & $0 / 6$ & $1 / 15$ & $2 / 13$ \\
\hline \multicolumn{4}{|l|}{ Cell structure (12/9) } \\
\hline Membrane components (6/3) & $2 / 0$ & $1 / 1$ & $3 / 2$ \\
\hline Murein sacculus, peptidoglycan (2/0) & $1 / 0$ & $0 / 0$ & $1 / 0$ \\
\hline Surface polysaccharides, lipopolysaccharides, and antigens (2/1) & $2 / 0$ & $0 / 1$ & $1 / 0$ \\
\hline Surface structures $(2 / 5)$ & $2 / 0$ & $2 / 4$ & $1 / 5$ \\
\hline \multicolumn{4}{|l|}{ Cellular processes $(9 / 15)$} \\
\hline Transport (8/12) & $4 / 0$ & $6 / 5$ & $3 / 11$ \\
\hline Cell division (1/3) & $1 / 0$ & $1 / 3$ & $0 / 1$ \\
\hline \multicolumn{4}{|l|}{ Mobile genetic elements $(16 / 7)$} \\
\hline Phage-related functions and prophages (8/1) & $2 / 0$ & $8 / 1$ & $6 / 0$ \\
\hline Plasmid-related functions (7/6) & $3 / 0$ & $6 / 6$ & $3 / 2$ \\
\hline Transposon- and intron-related functions (1/0) & $0 / 0$ & $0 / 0$ & $1 / 0$ \\
\hline Pathogenicity, virulence, and adaptation $(9 / 13)$ & $1 / 3$ & $6 / 8$ & $5 / 9$ \\
\hline Hypothetical (122/52) & $30 / 5$ & $73 / 34$ & $69 / 31$ \\
\hline ORFs with undefined category (3/4) & $1 / 0$ & $2 / 2$ & $0 / 2$ \\
\hline Total $(252 / 196)$ & $77 / 19$ & $156 / 139$ & $132 / 128$ \\
\hline
\end{tabular}

* Genes were categorized into functional classes according to the categories defined in the original annotation of the $X$. fastidiosa genome http://www.lbi.ic. unicamp.br/xf/.

\# The number of upregulated and downregulated genes, respectively, are indicated in parenthesis.

${ }^{\S}$ Number of genes upregulated and downregulated, respectively, during time points of the nitrogen starvation temporal series.

of intracellular amino acid depletion when $X$. fastidiosa cells were transferred to $\mathrm{XDM}_{0}$ medium. Increase in the levels of these enzymes might indicate that some functional categories containing differentially expressed genes (RNA metabolism, biosynthesis of amino acids and translation) were affected by the stringent response in addition to nitrogen starvation.

With the exception of the three genes described above (rocF, pip and pepQ), all other differentially expressed genes related to protein metabolism (16 genes) were repressed under nitrogen starvation (Table 1). Among them were genes encoding the major systems of chaperones and proteases of the cell, typical of the heat shock response, such as groEL, groES, hspA, dnaJ, dnaK, grpE,
$\operatorname{clpB}, m o p A, h t p X, h s p A$ and $m u c D$, and almost all were repressed during the three time-points of nitrogen starvation (Additional file 2: Table S2). These genes are transcribed by $\sigma^{32}$ in X. fastidiosa [23], but the rpoH gene encoding $\sigma^{32}$ was two-fold induced in the $8 \mathrm{~h}$ and $12 \mathrm{~h}$ periods. This strong repression by nitrogen starvation, at least for the groESL operon, could be mediated by the heat-inducible transcriptional repressor HrcA, once the $h r c A$ gene was four-fold induced in $2 \mathrm{~h}$. Severe downregulation in the expression of genes encoding chaperones and proteases of the heat shock response by nitrogen starvation was previously observed in $E$. coli [38]. Another interesting observation was the differential expression of a large number of genes (23 induced 
genes and 8 repressed genes) present in the pXF51 plasmid, most of them encoding proteins of the type IV secretion system, involved in bacterial conjugation [39].

\section{Identifying the RpoN regulon using DNA microarrays and in silico analysis}

In a previous work we have demonstrated, using microarray data, that few genes are downregulated in the rpoN mutant strain, when the experiments were performed in complex PWG medium. Under those experimental conditions, only the pilA1 gene (XF2542) seemed to be directly activated by $\sigma^{54}$, and probably in association with the two component system PilR/PilS [25]. To determine the effect of rpoN inactivation on gene expression after nitrogen starvation, the transcriptomes of the wild type and the rpoN strains were compared using DNA microarrays, with both strains grown on $\mathrm{XDM}_{2}$ medium and submitted to nitrogen starvation during 2 hours. Seven of the 22 differentially expressed genes were repressed, whereas 15 were induced in the rpoN mutant compared to the wild-type strain (Table 2). All seven genes positively regulated by $\sigma^{54}$ were differentially expressed under nitrogen starvation (Additional file 1: Table S1 and Additional file 2: Table S2). Among them, five (XF0180, XF1121, XF1819, XF2272 and XF2542) were induced in at least one point of the temporal series (Table 2 and Additional file 1: Table S1), indicating that these genes are induced under nitrogen starvation in a $\sigma^{54}$-dependent manner. Functional classification indicated four genes as related to amino acid metabolism. With the exception of the pilA1, which showed the highest decrease in expression in the rpoN mutant, all other genes were not detected in our previous microarray analysis as $\sigma^{54}$-regulated genes [25]. Given that sigma factors are activators of transcription, the overexpression of 15 genes in the rpoN mutant compared to the wild type strain might be the consequence of secondary regulatory effects originating from the rpoN mutation.

To potentially discriminate between genes directly and indirectly regulated by RpoN and to identify other members of the $\sigma^{54}$ regulon undetected by microarray analysis, we carried out an in silico search to locate potential RpoN-binding sites in $X$. fastidiosa genome. The

Table 2 Differentially expressed genes under nitrogen starvation in the rpoN mutant compared to the wild-type strain.

\begin{tabular}{|c|c|c|}
\hline Gene ID & Product $^{\S}$ & Ratio $\left(\log _{2}\right)^{\#}$ \\
\hline \multicolumn{3}{|c|}{ Downregulated genes (positively regulated by RpoN) } \\
\hline XF2542* & fimbrial protein & -3.79 \\
\hline XF2272* & 5-methyltetrahydropteroyltriglutamate homocysteine methyltransferase & -2.21 \\
\hline XF1819* & threonine dehydratase catabolic & -1.62 \\
\hline $\mathrm{XF1121^{* }}$ & 5,10-methylenetetrahydrofolate reductase & -1.51 \\
\hline XF2699 & transcription termination factor Rho & -1.37 \\
\hline XF0180* & hypothetical protein & -1.03 \\
\hline XF2207 & cationic amino acid transporter & -0.80 \\
\hline \multicolumn{3}{|c|}{ Upregulated genes (negatively regulated by RpoN) } \\
\hline XF1109 & hypothetical protein & 1.89 \\
\hline XF2343 & recombination protein $\mathrm{N}$ & 1.63 \\
\hline XF0887 & mannosyltransferase & 1.61 \\
\hline XF1830 & nitrile hydratase activator & 1.52 \\
\hline XF2551 & conserved hypothetical protein & 1.46 \\
\hline XF1658 & phage-related repressor protein & 1.30 \\
\hline XF1781 & hypothetical protein & 1.29 \\
\hline XF1117 & hypothetical protein & 1.24 \\
\hline XF2555 & lysyl-tRNA synthetase & 1.23 \\
\hline XF1469 & conserved hypothetical protein & 1.17 \\
\hline XF1078 & DNA uptake protein & 1.16 \\
\hline XF0412 & nitrate $A B C$ transporter ATP-binding protein & 1.14 \\
\hline XF0318 & NADH-ubiquinone oxidoreductase, NQO14 subunit & 1.08 \\
\hline XF0221 & hypothetical protein & 0.94 \\
\hline XF2377 & hypothetical protein & 0.81 \\
\hline
\end{tabular}

${ }^{5}$ Predicted function based on sequence similarity.

\# Log ratio of fluorescence intensity in strain rpoN compared to the $J 1$ a12 strain $\left[\log _{2}\left(I_{\text {rpoN }} / l_{\mathrm{J1a12}}\right)\right]$, both grown up under nitrogen starvation during two hours. Microarray analyses were carried out for three independent biological samples and a gene was classified as differentially expressed if at least four of its six replicates were outside the intensity-dependent cutoff curves.

* Genes induced under nitrogen starvation in at least one point of the temporal series. 
intergenic regions of the complete genome sequence of $X$. fastidiosa were scored against a strong position-specific weight matrix derived from 186 known $\sigma^{54}$-binding sites of 44 different bacterial species [18]. Considering only predicted sites with scores above the numerically calculated cutoff score (7.95), we were able to find 44 putative $\sigma^{54}$-binding sites or $\sigma^{54}$-dependent promoters that could potentially direct the transcription of a gene in the correct orientation. Their sequences with the associated genes or putative operons are summarized in Table 3. DNA sequence logo derived from these 44 predicted RpoN-binding sites shows two blocks of conserved sequences containing the highly frequent GG and GC dinucleotides (Figure 2), consistent with -24/-12type promoters recognized by $\mathrm{RpoN}$ in most of bacterial groups [18].

Functional classification of the genes associated to predicted RpoN-binding sites reveals the involvement of $\sigma^{54}$ with several cellular functions, such as motility, transcription regulation, transport, carbon metabolism and protein degradation among others. However, a large number of genes $(50 \%)$ encode proteins that have no attributed function (Table 3). The highest scoring RpoN-regulated promoter was located upstream of the pilA1 gene (XF2542), confirming a promoter previously characterized by primer extension analysis and the role of $\sigma^{54}$ in pili biogenesis [25]. The next best hit was found in front of a gene encoding a MarR transcriptional regulator (XF1354), the only regulatory gene associated with RpoN-binding site in our in silico analysis. MarR-like regulators control a variety of biological functions, including resistance to multiple antibiotics, organic solvents, sensing of aromatic compounds and regulation of virulence [40]. A regulatory gene belonging to $\sigma^{54}$ regulon could explain how RpoN might indirectly control the expression of genes that are not associated with RpoN-binding sites.

Predicted RpoN-binding sites were identified upstream of four putative operons encoding transport systems: two operons encoding translocases of the major facilitator superfamily (MSF) (XF1749-48-47-46 and XF160910-11), one operon encoding resistance-nodulation-cell division (RND) family efflux pump (XF2093-94) and the exbB-exbD-exbD2-XF0013 operon. Genes encoding transporters are regulated by sigma 54 in various bacteria such as E. coli [19], P. putida [20] and Rhizobiaceae [21], although most of these transporters are of the ATP-Binding Cassette (ABC) type. Other functional categories identified were carbon and energy metabolism (nио operon encoding NADH dehydrogenase and acnA encoding aconitase hydratase), biosynthesis of small molecules (XF1121, XF2677 and XF1315-relA-XF131718), DNA metabolism and translation. Possible RpoNbinding sites were also found upstream of two genes encoding putative peptidases (XF0220 and XF2260). In $E$. coli the $d d p X A B C D E$ operon (DdpX is a D-alanyl-Dalanine dipeptidase) is induced under nitrogen limitation, possesses a potential $\sigma^{54}$-dependent promoter and seems to work scavenging D-alanyl-D-alanine from peptidoglycan $[13,19]$. These results suggest that scavenging of nitrogen compounds could also be a mechanism controlled by $\sigma^{54}$ in $X$. fastidiosa.

To compare microarray data with in silico predictions, the genes and/or operons associated with the 44 predicted $\sigma^{54}$-binding sites were cross-examined with the list of genes induced under nitrogen starvation (Additional file 1: Table S1) and the genes with decreased expression levels in the wild type compared to its rpoN derivative mutant (Table 2). Genes encoding the pilin protein of the type IV pili (XF2542) and methylenetetrahydrofolate reductase (XF1121), an enzyme that catalyzes the conversion of methylenetetrahydrofolate to methyltetrahydrofolate, the major methyl donor for conversion of homocysteine to methionine were induced under nitrogen starvation, downregulated in the rpoN mutant and were preceded by $\sigma^{54}$-dependent promoters. A set of six genes possessing $\sigma^{54}$-dependent promoters (XF0220, XF0308, XF0318, XF0159, XF0567 and XF1316) was induced under nitrogen starvation, but they were not differentially expressed in the rpoN mutant. All other genes showed no consistent correlation between the transcriptome analysis and the computational promoter prediction. These apparent divergences can be attributable to low expression of RpoN- regulated genes unless under specific conditions that activate the enhancer binding proteins, suggesting that both methods are necessary to achieve a more complete description of the $X$. fastidiosa $\sigma^{54}$ regulon. These combined strategies have been applied to determine RpoN regulon in several bacteria, such as Listeria monocytogenes [41], Geobacter sulfurreducens [42] and Bradyrhizobium japonicum [43].

\section{Detection and validation of a $\sigma^{54}$-dependent promoter in the $g \ln A$ gene}

Analysis of genomic context indicates that Xylella possesses a conserved gene cluster predicted to encode proteins related to nitrogen metabolism including glutamine synthetase (XF1842), nitrogen regulatory protein P-II (XF1843), ammonium transporter (XF1844) and NtrB/NtrC two-component system (XF1848/ XF1849) (Figure 3A), all genes known to be part of the NtrC-RpoN regulon in E. coli $[13,19]$. In our original analysis using the PATSER program, only one RpoNbinding site was predicted in this region. It is located upstream of the XF1850 gene that encodes a hypothetical protein containing a conserved region of a probable transposase family (Table 3). It seems unlikely that this 
Table 3 Predicted RpoN-binding sites in X. fastidiosa genome.

\begin{tabular}{|c|c|c|c|c|}
\hline Gene ID & Position* & Sequence & Score & Product \\
\hline XF2542 & -76 & TGGCACACCTTCTGCT & 12.38 & fimbrial protein \\
\hline XF1354 & -122 & TGGTACGGTATTTGCT & 11.58 & MarR family transcriptional regulator \\
\hline XF0158 & -127 & CGGCACGTGTGTTGCT & 11.32 & hypothetical protein (XF0158-59-60) \\
\hline XF1842 $2^{\#}$ & -46 & TGGTATGCCAATTGCT & 10.52 & glutamine synthetase \\
\hline XF0623 & -246 & TGGCACGGGAATTGAA & 10.62 & hypothetical protein \\
\hline XF0220 & -129 & TGGGATGGTTCTTGCT & 10.46 & proline dipeptidase \\
\hline XF0178 & -177 & TGGCATGCCAAATGCA & 10.39 & conserved hypothetical protein (XF0178-79) \\
\hline XF0414 & -189 & TGGCGAGCATCTTGCA & 10.29 & hypothetical protein (XF0414-15) \\
\hline XF1850 & -7 & CGGCACATGCGTTGCT & 10.26 & hypothetical protein (probable transposase) \\
\hline XF1471 & -230 & CGGCACGGAATTCGCA & 10.22 & hypothetical protein \\
\hline XF1315 & -116 & AGGCACTGCGGTTGCA & 10.10 & hypothetical protein (XF1315-relA-XF1317-18) \\
\hline XF0746 & -227 & TGGCACTGCCAATGCA & 9.93 & hypothetical protein \\
\hline XF1121 & -82 & CGGCACGACCCCTGCC & 9.42 & 5,10-methylenetetrahydrofolate reductase \\
\hline XF0010 & -63 & TGGTCCGGCCAGTGCA & 9.36 & biopolymer transport ExbB protein (exbB-exbD-exbD2-XF0013) \\
\hline XF0507 & -213 & CGGCGCGGGTTTCGCT & 9.29 & hypothetical protein (XF0507-08) \\
\hline XF1784 & -151 & TGGCACGTCAAGCGCA & 9.26 & hypothetical protein (ParB-like nuclease domain) (XF1784-83-82-81) \\
\hline XF1943 & -342 & CGGCACGCTGATGGCA & 9.20 & histone-like protein \\
\hline XF0305 & -65 & GGGCACCATATTTGCT & 9.14 & NADH dehydrogenase subunit A (nuoABCDEFGHIJKLMN) \\
\hline XF1249 & -207 & CGGCCCGCAGCATGCT & 8.97 & hypothetical protein \\
\hline XF1749 & -27 & TGGCGCGGCGTTTCCT & 8.92 & MFS transporter (XF1749-48-47-46) \\
\hline XF0290 & -30 & CGGCACTGCCACTGCA & 8.90 & aconitate hydratase \\
\hline XF2580 & -109 & CGGCACGGAGGCGGCA & 8.81 & 30 S ribosomal protein $\mathbf{S 2}$ \\
\hline XF2639 & -43 & TGGCGCGCCACTTTCT & 8.79 & preprotein translocase subunit SecE (secE-nusG) \\
\hline XF0177 & -161 & TGGCCTGCATTTGGCA & 8.79 & hypothetical protein \\
\hline XF2260 & -305 & TGGAACAGAAGGTGCT & 8.75 & alanyl dipeptidyl peptidase \\
\hline XF1213 & -151 & CGGCTCCCCTCTTGCT & 8.74 & GTP-binding elongation factor protein \\
\hline XF2724 & -28 & TGGCACAGTGCCAGCA & 8.69 & type I restriction-modification system (XF2724-23-22-21) \\
\hline XF2677 & -164 & GGGCGTGATGCTTGCA & 8.65 & L-ascorbate oxidase \\
\hline XF1609 & -164 & TGGCAGGTGTTGTGCT & 8.60 & MFS glucose/galactose transporter (XF1609-10-11) \\
\hline XF2745 & -15 & CGGCGTGGCCGGTGCA & 8.59 & hypothetical protein \\
\hline XF0695 & -50 & AGGCGCGCCGTTCGCA & 8.59 & hypothetical protein \\
\hline XF1355 & -223 & TGGCAGTGCCGGTGCA & 8.51 & hypothetical protein \\
\hline XF2501 & -183 & CGGCACGGAGGGGGCA & 8.44 & hypothetical protein (phage-related protein) \\
\hline XF0710 & -183 & CGGCACGGAGGGGGCA & 8.44 & hypothetical protein (phage-related protein) \\
\hline XF2093 & -263 & TGGCATCCAAAGTGCA & 8.40 & HlyD family secretion protein (XF2093-94) \\
\hline XF1640 & -56 & TGGCAGTGCTACTGCA & 8.40 & ankyrin-like protein \\
\hline XF2008 & -44 & CGGCACGCAACACGCA & 8.30 & hypothetical protein \\
\hline XF2733 & -86 & TGGCAACCGCATTGCG & 8.28 & hypothetical protein \\
\hline XF2408 & -25 & AGGCCCCGCAGTTGCG & 8.28 & hypothetical protein (XF2408-09-10) \\
\hline XF0567 & -16 & TGGAGCACTCTITGCA & 8.22 & hypothetical protein \\
\hline XF2358 & -36 & TGGAACGCAATCTGCG & 8.17 & 235 rRNA 5-methyluridine methyltransferase \\
\hline XF0726 & -255 & TGGCGTGGTGGCCGCA & 8.14 & hypothetical protein (XF0726-27-28-29) \\
\hline XF2202 & -80 & GGGGATGGGTGTTGCT & 8.11 & hypothetical protein \\
\hline XF0625 & -46 & TGGAATTGCTATTGCT & 8.11 & hypothetical protein \\
\hline XF0641 & -179 & TGGCAAAGCGGTTGAA & 8.07 & DNA methyltransferase (XF0641-40) \\
\hline
\end{tabular}

* Distance between the -12 region of the promoter relative to the initiation codon.

\# Predicted RpoN-binding site detected upstream of the re-annotated initiation codon of XF1842 (g/nA). 


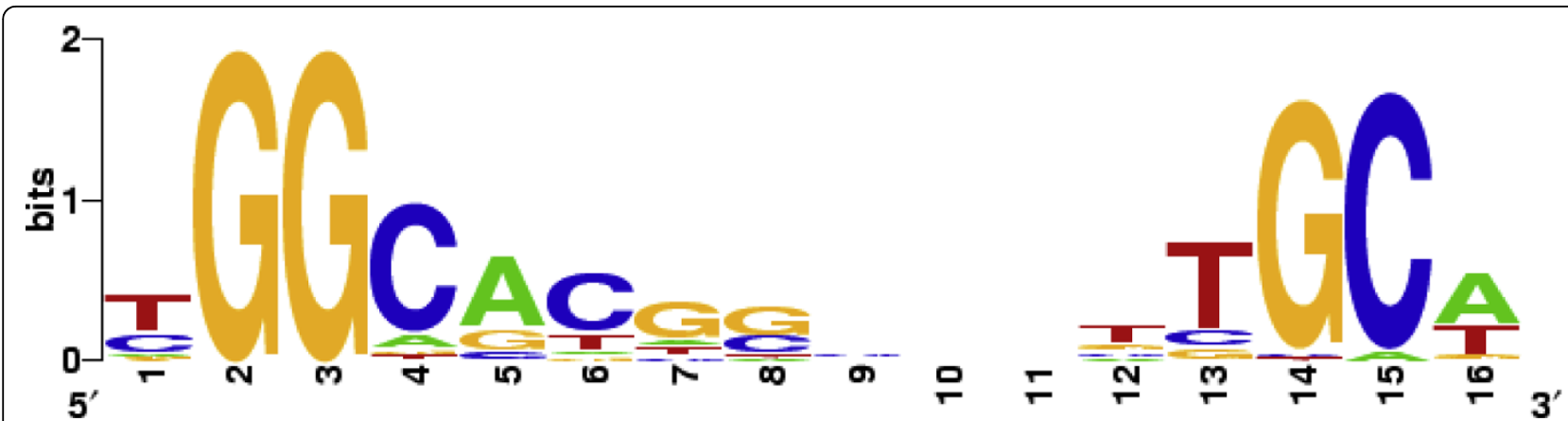

Figure 2 Sequence logo for Xylella RpoN-binding site. RpoN-binding sites predicted by PATSER (44 sites with score >7.95 shown in Table 3) were used to create the logo with the WebLogo generator http://weblogo.berkeley.edu/.

site regulates the $n t r B-n t r C$ operon, since there is a 376 bp-intergenic region between the two genes. Surprisingly, our global in silico prediction failed to detect RpoN-binding site upstream of the $g \ln A$ gene (XF1842), a well-known and widespread member of the $\sigma^{54}$ regulon [19]. However, a more detailed analysis, using ClustalW alignment, indicated that XF1842 ORF was annotated incorrectly and the coding sequence should be $108 \mathrm{bp}$ shorter than previously proposed. In silico analysis using the PATSER program in this new intergenic region detected a strong RpoN-binding site (score 10.52, Table 3).

To identify the 5 ' end of the $g \ln A$ transcript, primer extension assays were performed with total RNA isolated from the wild-type and rpoN mutant strains. One major cDNA product was observed corresponding to a single transcriptional start site at a cytosine located 35 bp upstream of the $g \ln A$ re-annotated initiation codon in the wild type strain, but no cDNA product was observed when primer extension experiments were performed with the rpoN mutant (Figure 3B). Upstream of the $g \ln A$ transcription start site we found the predicted RpoN-binding site, a sequence (TGGTATG-N4-TTGC) that is correctly positioned and matched 9 of 11 nucleotides to the $\sigma^{54}$ consensus sequence (TGGCACG-N4TTGC) (Figure 3C). In other bacteria, $\overline{g l n} A$ has a $\sigma^{54}$ dependent promoter and its transcription is regulated by the enhancer-binding protein $\mathrm{NtrC}$ [44]. Contact between the activator and the $\sigma^{54}$-RNA polymerase complex is achieved by DNA looping, facilitated either by the integration host factor (IHF) protein or by intrinsic DNA topology [45]. In fact, analysis of the regulatory region of the $g \ln A$ gene revealed the presence of ATrich sequences with perfect match for the IHF binding site (AATCAA-N4-TTG) besides two putative NtrCbinding sites (Figure 3C).

In conclusion, primer extension data indicate that $X$. fastidiosa $g \ln A$ gene has a single canonical $\sigma^{54}$-dependent promoter, confirming experimentally the in silico prediction. The fact that sequences related to the $\mathrm{NtrC}$ and IHF binding sites exist at appropriate positions upstream of the $g \ln A$ gene suggested that these factors act in concert with $\sigma^{54}$ to initiate $g \ln A$ transcription. Therefore, ammonium assimilation is a cellular process controlled by $\sigma^{54}$ in $X$. fastidiosa, similarly to that observed in enteric bacteria [12]. Although at high concentrations ammonium is toxic to many plants [46] and the main source of nitrogen in the xylem sap are amino acids [5], studies using more precise analytical techniques have detected significant amounts of ammonium in the xylem sap, showing that root-to-shoot ammonium translocation does indeed occur in plants [47]. The ammonium translocated by xylem vessels and that derived from protein catabolism should be used as nitrogen source by $X$. fastidiosa, through its incorporation into glutamine by glutamine synthetase.

\section{Conclusions}

In the present study, we used DNA microarrays to identify global gene expression changes during nitrogen starvation in $X$. fastidiosa. Nitrogen depletion in $\mathrm{XDM}_{2}$, a defined medium that contains amino acids as nitrogen source similarly to the xylem sap, resulted in major alterations in Xylella transcriptome. Changes in the expression were observed for several genes related to transport, RNA metabolism, biosynthesis of amino acids and translation, as well as a severe downregulation in the expression of genes related to heat shock response and carbon and energy metabolism. However, the function of several genes differentially expressed under nitrogen starvation remains unknown. In addition, we have also obtained a more detailed appreciation of the X. fastidiosa $\sigma^{54}$ regulon by combining computational prediction, microarray data and primer extension analysis. Among other cellular processes, RpoN controls pili biogenesis (pilA1) and ammonium assimilation $(g \ln A)$, consistent with the fact that $X$. fastidiosa has only two EBPs proteins encoding NtrC and PilR ortologues. 


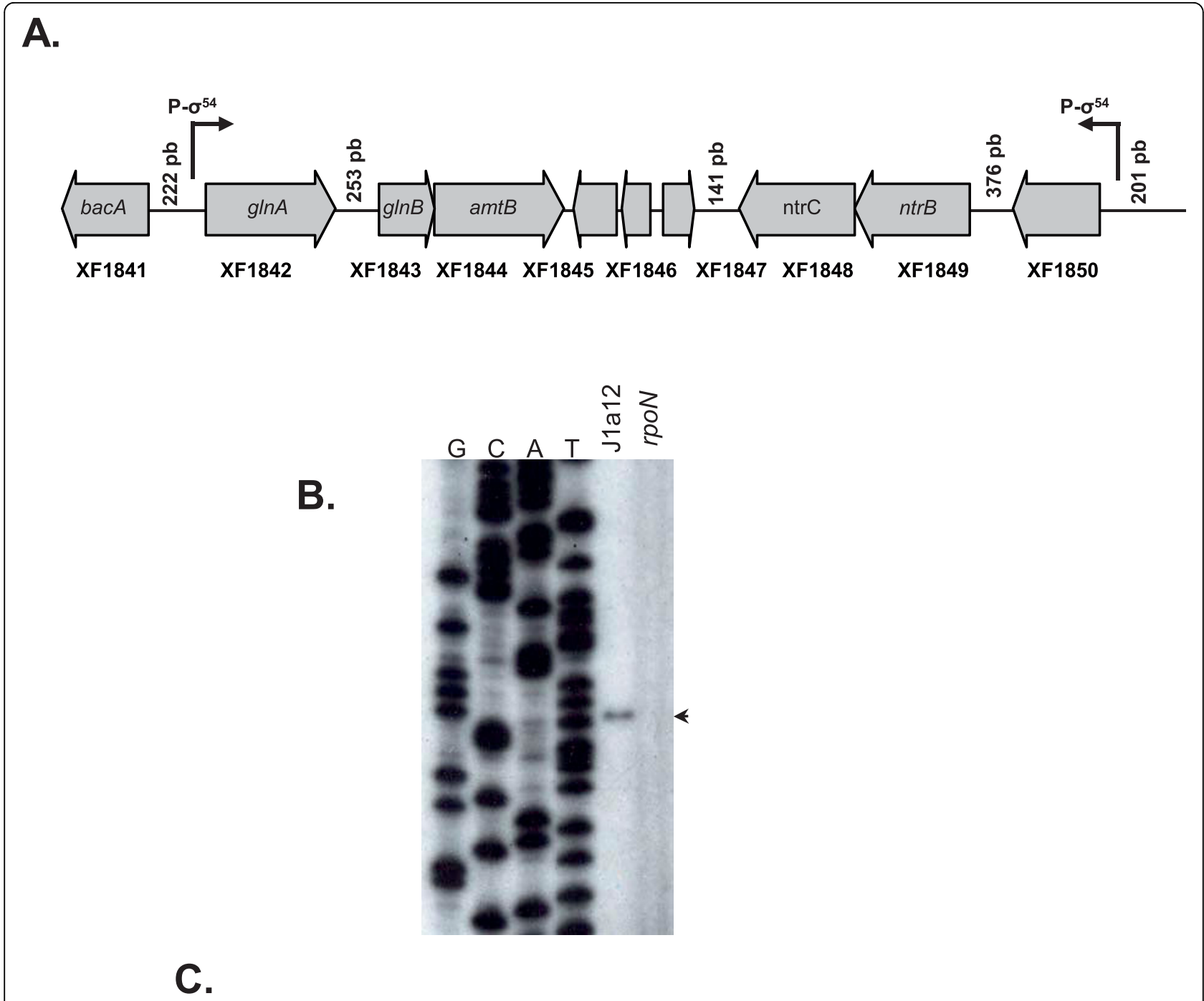

AACATGgGgGgATGgTtGAgAgCCAAAgGAGgGACAGCATAATCGATACATG AATGATCTGTAT:TGGTGGATTCAGGTTGGAGAGTTGCACCATATA_. TTCTAATGTAGATCATTAATGCTTACCCGAAAAAAACAATGGATTGCAAGG

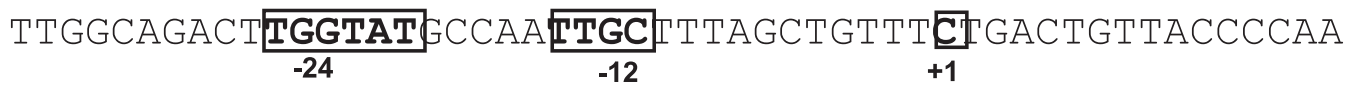
TCCTAAAAGGTTTCCTCTGATG

Figure 3 Characterization of a $\sigma^{54}$-dependent promoter in the $\mathbf{g} \ln A$ gene. (A). Genomic context of glnA gene in the $X$. fastidiosa chromosome indicating other genes associated with nitrogen metabolism. (B). Determination of the transcription start site of glnA by primer extension assay. Reactions were performed using total RNA from J1a12 and rpoN strains and the [ $\gamma$-32P]ATP-labeled primer XF1842EXT. A DNA sequencing ladder of phage M13mp18 was used as molecular size marker. The arrow indicates the band corresponding to the extended fragment. (C). Nucleotide sequence of $X$. fastidiosa glnA promoter region. The transcriptional start site determined by primer extension analysis and the -12 and -24 conserved sequence elements of the $\sigma^{54}$-dependent promoter are boxed. The re-annotated initiation codon (ATG) and the putative IHF binding site are underlined. The predicted Shine-Dalgarno sequence is double underlined. The putative NtrC binding sites are indicated by dashed lines. 
Experimental conditions that activate additional genes possessing true RpoN-binding sites remain to be determined.

\section{Additional material}

Additional file 1: Table S1: Upregulated genes under nitrogen starvation in $X$. fastidiosa J1a12 strain. The genes are ordered by the pattern of induction in the temporal series. $\mathrm{M}=\log$ ratio of fluorescence intensity in nitrogen starvation $\left(\mathrm{XDM}_{0}\right)$ compared to the control condition $\left(\mathrm{XDM}_{2}\right)$. The values of $\mathrm{M}$ considered upregulated are highlighted in bold.

Additional file 2: Table S2: Downregulated genes under nitrogen starvation in $X$. fastidiosa J1a12 strain. The genes are ordered by the pattern of repression in the temporal series. $M=\log$ ratio of fluorescence intensity in nitrogen starvation $\left(X_{D} M_{0}\right)$ compared to the control condition $\left(\mathrm{XDM}_{2}\right)$. The values of $\mathrm{M}$ considered downregulated are highlighted in bold.

\section{Acknowledgements}

This work was supported by a grant from Fundação de Amparo à Pesquisa do Estado de São Paulo (FAPESP). During the course of this work, JFSN and TK were supported by predoctoral fellowships from FAPESP. MVM and SLG are partly supported by Conselho Nacional de Desenvolvimento Científico e Tecnológico (CNPq).

\section{Author details}

'Departamento de Microbiologia, Instituto de Ciências Biomédicas, Universidade de São Paulo, Av. Prof. Lineu Prestes 1374, 05508-000 São Paulo, SP, Brazil. ${ }^{2}$ Departamento de Bioquímica, Instituto de Química, Universidade de São Paulo, Av. Prof. Lineu Prestes 748, 05508-000 São Paulo, SP, Brazil. ${ }^{3}$ Departamento de Bioquímica e Imunologia, Faculdade de Medicina de Ribeirão Preto, Universidade de São Paulo, Av. dos Bandeirantes 3900, 14049-900 Ribeirão Preto, SP, Brasil.

\section{Authors' contributions}

JFSN designed and performed the experimental work and wrote the manuscript. TK analyzed the microarray data. MVM and SLG participated in study design and coordination and helped to draft the manuscript. All authors read and approved the final manuscript.

\section{Received: 26 April 2010 Accepted: 28 August 2010}

Published: 28 August 2010

\section{References}

1. Hopkins DL, Purcell AH: Xylella fastidiosa: cause of Pierce's disease of grapevine and other emerging diseases. Plant Dis 2002, 86:1056-1066.

2. Chatterjee S, Almeida RPP, Lindow S: Living in two worlds: the plant and insect lifestyles of Xylella fastidiosa. Annu Rev Phytopathol 2008, 46:243-271.

3. Andersen PC, Brodbeck BV, Oden S, Shriner A, Leite B: Influence of xylem fluid chemistry on planktonic growth, biofilm formation and aggregation of Xylella fastidiosa. FEMS Microbiol Lett 2007, 274:210-217.

4. Zaini PA, De La Fuente L, Hoch HC, Burr TJ: Grapevine xylem sap enhances biofilm development by Xylella fastidiosa. FEMS Microbiol Lett 2009, 295:129-134.

5. Lea PJ, Sodek L, Parry MAJ, Shewry PR, Halford NG: Asparagine in plants. Annals of Applied Biology 2007, 150:1-26.

6. Purcino RP, Medina CL, Martins de Souza D, Winck FV, Machado EC, Novello JC, Machado MA, Mazzafera P: Xylella fastidiosa disturbs nitrogen metabolism and causes a stress response in sweet orange Citrus sinensis cv. Pera. J Exp Bot 2007, 58:2733-2744.

7. Silberbach M, Hüser A, Kalinowski J, Pühler A, Walter B, Krämer R, Burkovski A: DNA microarray analysis of the nitrogen starvation response of Corynebacterium glutamicum. J Biotechnol 2005, 119:357-367.
8. Osanai T, Imamura S, Asayama M, Shirai M, Suzuki I, Murata N, Tanaka K: Nitrogen induction of sugar catabolic gene expression in Synechocystis sp. PCC 6803. DNA Res 2006, 13:185-195.

9. Tolonen AC, Aach J, Lindell D, Johnson ZI, Rector T, Steen R, Church GM, Chisholm SW: Global gene expression of Prochlorococcus ecotypes in response to changes in nitrogen availability. Mol Syst Biol 2006, 2:53.

10. Ehira S, Ohmori M, Sato N: Genome-wide expression analysis of the responses to nitrogen deprivation in the heterocyst-forming cyanobacterium Anabaena sp. strain PCC 7120. DNA Res 2003, 10:97-113.

11. Burkovski A: Ammonium assimilation and nitrogen control in Corynebacterium glutamicum and its relatives: an example for new regulatory mechanisms in actinomycetes. FEMS Microbiol Rev 2003, 27:617-628.

12. Reitzer L: Nitrogen assimilation and global regulation in Escherichia coli. Annu Rev Microbiol 2003, 57:155-176.

13. Zimmer DP, Soupene E, Lee HL, Wendisch VF, Khodursky AB, Peter BJ, Bender RA, Kustu S: Nitrogen regulatory protein C-controlled genes of Escherichia coli: scavenging as a defense against nitrogen limitation. Proc Natl Acad Sci USA 2000, 97:14674-1467.

14. England JC, Perchuk BS, Laub MT, Gober JW: Global regulation of gene expression and cell differentiation in Caulobacter crescentus in response to nutrient availability. J Bacteriol 2010, 192:819-833.

15. Buck M, Gallegos MT, Studholme DJ, Guo Y, Gralla JD: The bacterial enhancer-dependent sigma(54) (sigma(N)) transcription factor. J Bacteriol 2000, 182:4129-4136.

16. Studholme DJ, Dixon R: Domain architectures of sigma54-dependent transcriptional activators. J Bacteriol 2003, 185:1757-1767.

17. Merrick MJ: In a class of its own - the RNA polymerase sigma factor sigma 54 (sigma N). Mol Microbiol 1993, 10:903-909.

18. Barrios H, Valderrama B, Morett E: Compilation and analysis of sigma(54)dependent promoter sequences. Nucleic Acids Res 1999, 27:4305-4313.

19. Reitzer L, Schneider BL: Metabolic context and possible physiological themes of sigma(54)-dependent genes in Escherichia coli. Microbiol Mol Biol Rev 2001, 65:422-444

20. Cases I, Ussery DW, De Lorenzo V: The sigma54 regulon (sigmulon) of Pseudomonas putida. Environ Microbiol 2003, 5:1281-1293.

21. Dombrecht B, Marchal K, Vanderleyden J, Michiels J: Prediction and overview of the RpoN-regulon in closely related species of the Rhizobiales. Genome Biol 2002, 3:0076.1-0076.11.

22. Simpson AJ, Reinach FC, Arruda P, Abreu FA, Acencio M, Alvarenga R, Alves LM, Araya JE, Baia GS, Baptista CS, Barros MH, Bonaccorsi ED, Bordin S, Bové JM, Briones MR, Bueno MR, Camargo AA, Camargo LE, Carraro DM, Carrer H, Colauto NB, Colombo C, Costa FF, Costa MC, Costa-Neto CM, Coutinho LL, Cristofani M, Dias-Neto E, Docena C, El-Dorry H, Facincani AP, Ferreira AJ, Ferreira VC, Ferro JA, Fraga JS, França SC, Franco MC, Frohme M, Furlan LR, Garnier M, Goldman GH, Goldman MH, Gomes SL, Gruber A, Ho PL, Hoheisel JD, Junqueira ML, Kemper EL, Kitajima JP, Krieger JE, Kuramae EE, Laigret F, Lambais MR, Leite LC, Lemos EG, Lemos MV, Lopes SA, Lopes CR, Machado JA, Machado MA, Madeira AM, Madeira HM, Marino CL, Marques MV, Martins EA, Martins EM, Matsukuma AY, Menck CF, Miracca EC, Miyaki CY, Monteriro-Vitorello CB, Moon DH, Nagai MA, Nascimento AL, Netto LE, Nhani A Jr, Nobrega FG, Nunes LR, Oliveira MA, de Oliveira MC, de Oliveira RC, Palmieri DA, Paris A, Peixoto BR, Pereira GA, Pereira HA Jr, Pesquero JB, Quaggio RB, Roberto PG, Rodrigues V, de M Rosa AJ, de Rosa VE Jr, de Sá RG, Santelli RV, Sawasaki HE, da Silva AC, da Silva AM, da Silva FR, da Silva WA Jr, da Silveira JF, Silvestri ML, Siqueira WJ, de Souza AA, de Souza AP, Terenzi MF, Truffi D, Tsai SM, Tsuhako MH, Vallada H, Van Sluys MA, Verjovski-Almeida S, Vettore AL, Zago MA, Zatz M, Meidanis J, Setubal JC: The genome sequence of the plant pathogen Xylella fastidiosa. Nature 2000, 406:151-157.

23. Koide T, Vencio RZN, Gomes SL: Global gene expression analysis of the heat shock response in the phytopathogen Xylella fastidiosa. J Bacteriol 2006, 188:5821-5830.

24. da Silva Neto JF, Koide T, Gomes SL, Marques MV: The single extracytoplasmic-function sigma factor of Xylella fastidiosa is involved in the heat shock response and presents an unusual regulatory mechanism. J Bacteriol 2007, 189:551-560.

25. da Silva Neto JF, Koide T, Abe CM, Gomes SL, Marques MV: Role of sigma54 in the regulation of genes involved in type I and type IV pili biogenesis in Xylella fastidiosa. Arch Microbiol 2008, 189:249-261. 
26. Monteiro PB, Teixeira DC, Palma RR, Garnier M, Bové JM, Renaudin J: Stable transformation of the Xylella fastidiosa citrus variegated chlorosis strain with oriC plasmids. Appl Environ Microbiol 2001, 67:2263-2269.

27. Davis MJ, French WJ, Schaad NW: Axenic culture of the bacteria associated with phony peach disease of peach and plum leaf scald. Current Microbiol 1981, 6:309-314.

28. Lemos EG, Alves LM, Campanharo JC: Genomics-based design of defined growth media for the plant pathogen Xylella fastidiosa. FEMS Microbiol Lett 2003, 219:39-45.

29. Koide T, Zaini PA, Moreira LM, Vêncio RZ, Matsukuma AY, Durham AM, Teixeira DC, El-Dorry H, Monteiro PB, da Silva AC, Verjovski-Almeida S, da Silva AM, Gomes SL: DNA microarray-based genome comparison of a pathogenic and a nonpathogenic strain of Xylella fastidiosa delineates genes important for bacterial virulence. J Bacteriol 2004, 186:5442-5449.

30. Yang YH, Dudoit S, Luu P, Lin DM, Peng V, Ngai J, Speed TP: Normalization for CDNA microarray data: a robust composite method addressing single and multiple slide systematic variation. Nucleic Acids Res 2002, 30:e15.

31. Vencio RZN, Koide T: HTself: Self-Self Based Statistical Test for Low Replication Microarray Studies. DNA Res 2005, 12:211-214.

32. Hertz GZ, Stormo GD: Identifying DNA and protein patterns with statistically significant alignments of multiple sequences. Bioinformatics 1999, 15:563-577.

33. Thomas-Chollier M, Sand O, Turatsinze JV, Janky R, Defrance M, Vervisch E, Brohée $S$, van Helden J: RSAT: regulatory sequence analysis tools. Nucleic Acids Res 2008, 36:W119-W127.

34. Crooks GE, Hon G, Chandonia JM, Brenner SE: WebLogo: a sequence logo generator. Genome Res 2004, 14:1188-1190.

35. Riley M: Functions of the gene products of Escherichia coli. Microbiol Rev 1993, 57:862-952.

36. Silberbach M, Burkovski A: Application of global analysis techniques to Corynebacterium glutamicum: New insights into nitrogen regulation. Biotechnol 2006, 126:101-110.

37. Srivatsan A, Wang JD: Control of bacterial transcription, translation and replication by (p)ppGpp. Curr Opin Microbiol 2008, 11:100-105.

38. Kabir MS, Sagara T, Oshima T, Kawagoe Y, Mori H, Tsunedomi R, Yamada M: Effects of mutations in the rpoS gene on cell viability and global gene expression under nitrogen starvation in Escherichia coli. Microbiology 2004, 150:2543-2553.

39. Marques MV, da Silva AM, Gomes SL: Genetic organization of plasmid pXF51 from the plant pathogen Xylella fastidiosa. Plasmid 2001, 45:184-199.

40. Ellison DW, Miller VL: Regulation of virulence by members of the MarR/ SlyA family. Curr Opin Microbiol 2006, 9:153-159.

41. Arous $S$, Buchrieser $C$, Folio P, Glaser $P$, Namane A, Hébraud M, Héchard $Y$ : Global analysis of gene expression in an rpoN mutant of Listeria monocytogenes. Microbiology 2004, 150:1581-1590.

42. Leang C, Krushkal J, Ueki T, Puljic M, Sun J, Juárez K, Núñez C, Reguera G, DiDonato R, Postier B, Adkins RM, Lovley DR: Genome-wide analysis of the RpoN regulon in Geobacter sulfurreducens. BMC Genomics 2009, 10:331.

43. Hauser F, Pessi G, Friberg M, Weber C, Rusca N, Lindemann A, Fischer HM Hennecke $H$ : Dissection of the Bradyrhizobium japonicum NifA $+\sigma^{54}$ regulon, and identification of a ferredoxin gene $(f d x N)$ for symbiotic nitrogen fixation. Mol Genet Genomics 2007, 278:255-271.

44. Reitzer $\sqcup$, Magasanik B: Transcription of $g \ln A$ in E. coli is stimulated by activator bound to sites far from the promoter. Cell 1986, 45:785-792.

45. Craig NL, Nash HA: E. coli integration host factor binds to specific sites in DNA. Cell 1984, 39:707-716.

46. Britto DT, Siddiqi MY, Glass ADM, Kronzucker HJ: Futile transmembrane $\mathrm{NH}_{4}$ cycling: A cellular hypothesis to explain ammonium toxicity in plants. PNAS 2001, 98:4255-4258.

47. Schjoerring JK, Husted S, Mack G, Mattsson M: The regulation of ammonium translocation in plants. J Exp Bot 2002, 53:883-890.

doi:10.1186/1471-2180-10-231

Cite this article as: da Silva Neto et al:: Global gene expression unde nitrogen starvation in Xylella fastidiosa: contribution of the $\sigma^{54}$ regulon. BMC Microbiology 2010 10:231.

\section{Submit your next manuscript to BioMed Central and take full advantage of:}

- Convenient online submission

- Thorough peer review

- No space constraints or color figure charges

- Immediate publication on acceptance

- Inclusion in PubMed, CAS, Scopus and Google Scholar

- Research which is freely available for redistribution

Submit your manuscript at www.biomedcentral.com/submit 